\title{
Pediatric safety on farms: redefining the unacceptable
}

\author{
Lesley Day
}

$\infty$

See related article page 1723

$\mathrm{T}$

he universality of our desire to nurture and protect children is reflected in the many programs that address the major health and economic issues faced by children worldwide. The stereotypical view of farms as wholesome, healthy places for children to grow and learn can mask from us the dangers posed to young children in work environments. Nevertheless, recognition is growing in many countries that children on farms are at higher risk of fatal and serious injury than their city cousins.

The article by Brison and colleagues ${ }^{1}$ in this issue brings the problem of agriculture-related injuries to young children in Canada into sharp relief. They found that young children on farms and ranches in Canada, particularly boys, are about twice as likely as young Canadian children altogether to die of an injury. Furthermore, most of these fatal injuries occurred in the worksite and involved being run over by agricultural machinery (as either a bystander or a passenger who fell from the machinery) or drowning. Similar mechanisms of fatal pediatric injury have been reported in the United States, Australia and New Zealand (although drowning deaths made up a higher proportion in those countries). ${ }^{2-4}$

This research is important for 2 reasons. First, not only does it quantify the extent to which young farm children in Canada are at a higher risk of dying from an injury than the general population of young Canadian children, it also provides some insights into the circumstances of these fatal events. Hence, it creates the opportunity to improve the specificity of communication about risk to young children, especially boys, of families involved in the farming community. Second, it creates the opportunity for discussion and debate about the best strategies with which to protect young children on Canadian farms and ranches.

The study found that the majority of agriculture-related child deaths in Canada are the result of young children accompanying adults into the agricultural workplace. The authors have suggested that removal of young children from the vicinity of known farm hazards is a solution. As simple a strategy as this is, its implementation is far from uncomplicated.

Young children may be taken into the farm workplace for a variety of reasons. One is inadequate child care. In a survey of 4I8 farm families in Australia, among those who reported adequate or mostly adequate access to child care, $46 \%$ reported that children are always, often or sometimes looked after in 5 the farm or ranch workplace. ${ }^{5}$ The desire to share the wonders of the natural world on farms (where opportunities are so abundant), and the tradition of familiarizing children with farm work as a prelude to more formal training, are also part of farm family life - often a central part. A strategy based on removing children from the work site must be balanced by components that provide viable alternatives for maintaining

the essence of farm family life. For example, practices such as bringing 1 or 2 small animals at a time into the farmhouse yard for young children to see and touch could replace taking young children out into the barn or onto other parts of the farm to see the animals.

In response to the incidence of farm-related pediatric injuries, Farmsafe Australia developed a broad strategy for child safety on farms and ranches, which, in cooperation with several partner agencies, has recently been implemented. ${ }^{5}$ The strategy includes recommendations for removal of drowning hazards where possible, creation of fenced-in safe play areas, and a family rule that young children remain in the house and yard unless an adult takes them out and keeps them close by holding their hand. ${ }^{5}$ The range of resource material available is comprehensive and includes information for farm families about child development, agricultural injury risk and safe fencing options. ${ }^{\circ}$

The idea of actually prohibiting young children from the agricultural worksite was raised by Brison's group ${ }^{1}$ although how this might be done (via legislation or a voluntary code of practice) was not addressed. Certainly, legislation can be a powerful component of an injury-prevention strategy, particularly in improving product safety and regulating behaviour in the public domain (e.g., the wearing of seat belts and cycle helmets on roadways). Would legislation achieve the desired end in this instance?

\section{Alternatives must be pro- vided to maintain the es- sence of farm family life.}

Possibly not, in the current environment. Experience in the field of injury prevention, including that in agricultural settings, suggests as well that legislation of individual behaviour is most effective when there is already considerable acceptance within the community that the end would justify the means. The wearing of bicycle helmets by primary schoolaged children and adults in Victoria, Australia, increased substantially during the 7 years before the introduction of legislation, through a combination of helmet promotion, professional and community support and consultation, and financial incentives. ${ }^{7}$ Further increases in helmet-wearing took place after the legislation was passed. A similar approach increased protection from tractor rollovers; in that case, a law requiring the retrofit of rollover frames was not 
introduced until the Victorian Farmers Federation formally accepted and supported its introduction. ${ }^{8}$

The importance of some degree of community acceptance of legislative action is illustrated by an example of a failed prosecution in Australia. Under the occupational health and safety legislation in all Australian states, business operators have a duty to protect the health and safety of everyone who enters the workplace, including visitors such as young children. Some years ago, WorkSafe Western Australia initiated prosecution of a farmer after his 13-year-old daughter died in an incident that involved an auger. Community outrage ensued, which resulted in the introduction of a requirement for a test of public interest to be applied to public prosecutions. In this case, prosecution was deemed to be not in the public interest and the action was withdrawn. ${ }^{9}$ In New South Wales, legislation enacted to require isolation fencing of domestic swimming pools was repealed 2 years later after intense lobbying and media advocacy by pool owners. ${ }^{10}$ In the United States, motorcycle legislation was similarly rescinded in the mid-r97os. ${ }^{11}$

The question of whether voluntary action in keeping young children away from workplaces on farms and ranches would reduce child deaths could evoke a similar answer: probably not immediately. However, there are precedents in public health of major successes arising from voluntary changes in behaviour, such as the reduction in HIV transmission rates effected with behaviour-modification programs relating to condoms and clean needles. Such success usually arises from redefinition of the unacceptable. ${ }^{12}$ Where unprotected sex and needle-sharing was once accepted as normal behaviour, the community (in particular, those at high risk) now define these behaviours as unacceptable and act accordingly. Dob$\operatorname{son}^{12}$ posited that the process of redefining the unacceptable starts when members of a community realize the severity of outcomes of a health-related condition or behaviour and perceive themselves as vulnerable. As Brison and colleagues have suggested, ${ }^{1}$ physicians and allied health professionals can play an important role in this process, raising awareness among families of the extent of fatalities among young children on farms and ranches, and contributing to the redefinition of acceptable practice in relation to children in the farm workplace by recommending that young children not be taken or allowed to go there. Health professionals have a proud history of advocating for the protection of the public's health. Armed with Brison and colleagues' data, Canadians have the opportunity to create a different future for young farm children.

This article has been peer reviewed.

Dr. Lesley Day is supported by a Senior Research Fellowship from the National Health and Medical Research Council of Australia and is based at Monash University, Melbourne, Australia.

Competing interests: None declared.

Acknowledgements: I am grateful to Cathy Daly for her assistance in retrieving background information for this article.

\section{REFERENCES}

I. Brison RJ, Pickett W, Berg RL, et al. Fatal agricultural injuries in preschool children risks, injury patterns, and strategies for prevention. $C M A J$ 2006;I74(I2):I723-6.

2. Rivara FP. Fatal and non-fatal farm injuries to children and adolescents in the United States, 1990-3. Inj Prev 1997;3:190-4.

3. Clarke JA, Marshal SW, Langley JD, et al. Epidemiology of injuries occurring on New Zealand farms. Dunedin, New Zealand: Injury Prevention Research Unit, University of Otago; I995.

4. Mitchell RJ, Franklin RC, Driscoll TR, et al. Farm-related fatalities involving children in Australia, I989-I992. Aust N Z J Public Health 200I; 25:307-I4.

5. Australian Centre for Agricultural Health and Safety. National Child Safety on Farms Project final report. Moree, Australia: The Centre, 2005.

6. Farmsafe Australia Inc. Available: www.farmsafe.org.au (accessed 2006 April Io).

7. Cameron MH, Vulcan AP, Finch CF, et al. Mandatory bicycle helmet use following a decade of helmet promotion in Victoria, Australia - an evaluation. Accid Anal Prev I994;26:325-37.

8. Day L, Rechnitzer G, Lough J. An Australian experience with tractor rollover protective structure rebate programs: process, impact and outcome evaluation. Accid Anal Prev 2004;36:86I-7.

9. Ministerial Offices, Australian Ministry of Labour Relations. Prosecution policies [media releases]. WorkSafe Western Australia; I997. Available: www.safetyline.wa .gov.au/pagebin/wswamedaorg8a.pdf (accessed 2006 April ro). pp. 2I-5.

Io. Carey V, Chapman S, Gaffney D. Children's lives or garden aesthetics? A case study in public health advocacy. Aust J Public Health I994; I8:25-32.

II. National Committee for Injury Prevention and Control. Injury prevention: meeting the challenge. Am J Prev Med ig89;5(Suppl 3):I-303.

I2. Dobson A. Redefining the unacceptable. Aust J Public Health 1994; 18:9-I4

Correspondence to: Dr. Lesley Day, Accident Research Centre, Building 70, Monash University, Clayton, VIC 3800 , Australia; fax oII 6I 03 9905-I809; lesley.day@muarc.monash.edu.au

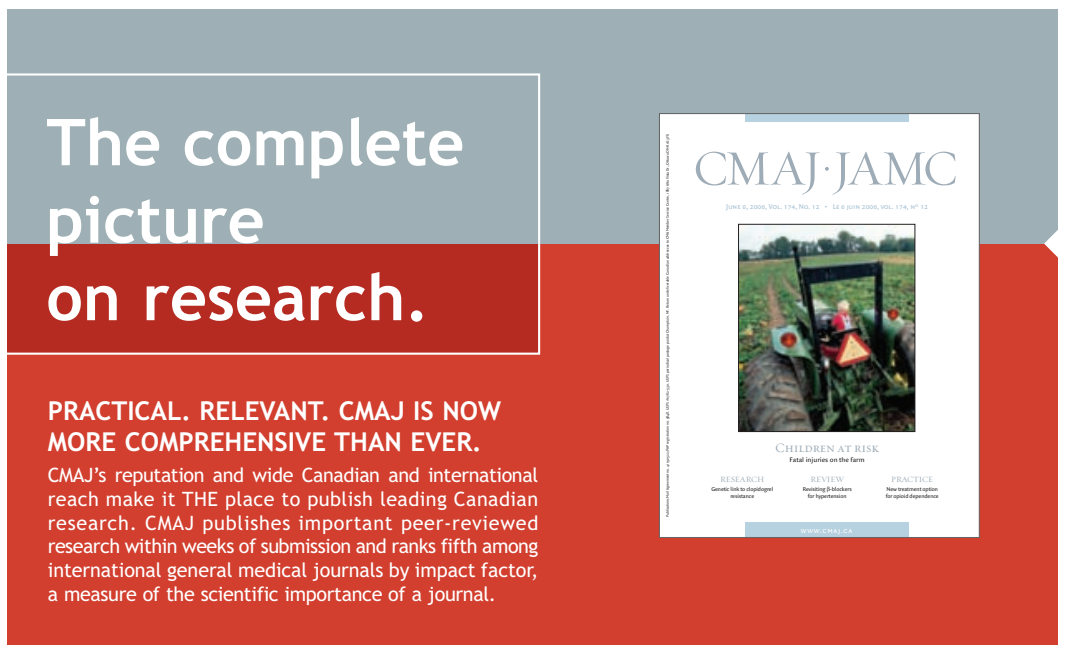

The essential read. ${ }^{\mathrm{m}}$ 